\title{
A Semiotic-based Approach as an Effective Tool for Teaching Verbal and Non-verbal Aspects of Language
}

\author{
Ibrahim Mohammad Abushihab \\ English Department, Al-Zaytoonah Private University of Jordan, Jordan \\ Email: Ibrashihab@yahoo.com
}

\begin{abstract}
Language as a means of communication has been the target of many scholars and linguists such as Saussure (1913), Jakobson (1974), Chomsky (1957) among others. Such scholars and Linguists have discussed the important aspects of Language focusing on the relationship between the signs (signifiers) and objects (signified) (Pierce cited in Ibrahim, 2005:10). Linguistics is used to tackle the non-linguistic signs, i.e. the visual signs, and gestures as well. This paper deals with the basic principles and insights of semiotics and its possible application to foreign language learning settings. It is hoped that the findings of this paper will raise awareness of teachers as a foreign language to what constitutes the semiotic approach and how to apply it.
\end{abstract}

Index Terms — semiotics, signs, body language, communication, teaching

\section{INTRODUCTION}

Semiotics is the science of signs, of symbolic behavior or of communication system (Lyons, 2004, p.17). As mentioned above, much research has been conducted on the semiotic perspective, but there has been very little discussion of the application of semiotic insights to education. Papers like this would lead to the emergence of a new field of study called educational semiotics.

Chomsky discusses the relationship between the linguistic and non-linguistic aspects in human life. He focuses on the view that language learning/acquisition is a process of self-investigation, of knowing how the mechanism of the human mind functions. He elaborates that "Language learning is nothing more than what human minds construct when placed in appropriate conditions; they are designed in anything like the same way to learn physics." (Chomsky, 1979, p.35).

Communication, meanwhile, is the exchange of ideas between two or more people. All forms of communication can be categorized as verbal or non-verbal. Much of the communication that takes place among people is verbal. Verbal communication is a conversation between two or more individuals in which they use their speech organs to convey the message. Non-verbal communication is the process of communication among individuals through wordless messages. Such messages can be sent through gestures, body language, facial expressions, eye contact and signs.

\section{VERBAL COMMUNiCATION}

Much controversy has been raised about the validity of language as a means of communication. Man has been differentiated from other creatures in that he uses language for communication. Fromkin et al (2003) assure:

Humans use speech sounds to communicate with each other and to express meanings, but such sounds are not necessary to be an aspect of language, as evidenced by the sign languages (p.23).

According to many scholars, animals, birds and insects like monkeys, dolphins and bees can communicate without language. "The chirping of birds, the squeaking of dolphins and the dancing of bees may potentially represent system similar to human languages. If animal communication systems are not like human language, it will not be due to a lack of speech." (Fromkin et al, ibid, p.23)

In order to be able to communicate, people should be communicatively competent. Johnson and Johnson (1999) talk about four major components of communicative competence:

Grammatical competence, sociolinguistic competence, discourse competence and strategic competence. Grammatical competence includes knowledge of vocabulary, rules of words and sentence formation, linguistics, semantics, pronunciation and spelling. Sociolinguistic competence includes rules of appropriateness of both meanings and grammatical forms in different sociolinguistic contexts. Discourse competence includes the knowledge required to combine forms and meanings to achieve coherent spoken and written text (pp.62-65).

Al-Mutawa and Kailani (1994) stress that the discourse strategy involves the following aspects:

a. Cohesion: This is the creation of ties between sentences by lexical and grammatical means.

b. Coherence: This is a way in which structure is created in texts as in sequential Logic of speech acts.

c. Gambits: These are words and expressions that help regulate conversation, e.g. well, now, oh, yes, etc. 
d. Turn-taking: In conversations and dialogues, this refers to the role-changing process from one speaker to another (p. 168).

They also state

The strategic competence is the speaker's ability to solve communication problems by means of strategies. The term covers problem solving devices that learners resort to in order to solve what they experience as problems in speech production and reception. (ibid, p. 198).

Saussure (1913) (cited in Dinneen 1979, p.967) considers language as a phenomenon of two fundamental dimensions: Langue and Parole. The distinction between langue and parole relates to the abstract language system which is called language and the individual utterances made by the speakers of language which are called speech. Parole is defined as what people say. He does not view speaking as a social fact, since it is put under conscious level and it is fully an individual output; a social fact should be used by the entire community. Saussure (1913) states that langue is both a social product of the faculty of speech and a collection of necessary conventions that have been adopted by a social body to permit individuals to exercise this faculty (cited in Hawkes, 2004, p.10). Langue is a set of habits we have been taught by our speech community.

Chomsky's Generative Grammar theory (1957) was a turning point in the twentieth century. He applied Generative Grammar to linguistics with a heavy attack on Structural Grammar. According to the principles of Structuralism, sentences in a text are analyzed under the nine basic patterns and all sentences are subjected to these patterns. Generative Grammar takes advantage of the Structural Grammar to interpret sentences of the same structure, but of different meanings as follows:

John is easy to please.

and

John is eager to please.

Both examples belong to the same grammatical pattern: (Noun $+\mathrm{Be}+$ Adjective + Infinitive) with different meanings. Structural grammar does not account for these differences.

A major aim of generative grammar is to provide a means of generating sentences. To achieve this aim, Chomsky draws a fundamental distinction between competence and performance. He thinks of competence as the subconscious knowledge of a set of internal rules while performance is what the speaker actually produces (ibid). Sociolinguistics emphasizes that the EFL learners' communicative competence will remain inadequate unless they are familiar with the appropriate contexts in which the foreign language is used. Ignorance of the cultural features of the foreign language would create instances of misunderstanding or the collapse of the communication process.

\section{NON-VERBAL COMMUNICATION}

As a means of communication, language transmits knowledge and ideas from one individual to another. A great deal of our communication is in a non - verbal form which is transmitted through sign language or other similar alternatives to verbal language. In philosophy, "sign" envisages notions such as symbols, symptoms and signals. It is used in an allinclusive sense as when semiotics is defined as the science of signs (Crystal, 1992, p. 316).

The concept of a sign language is defined as a set of gestures being used in place of a real language. Yule (2001) remarks that "sign language is a system of gestures developed by a speaker for limited communication in a specific context where speech cannot be used" (p. 202).

Saussure (1857-1913) was the first to introduce the term linguistic signs. He records in his Course de Linguistique General (Paris, 1913; translated by Baskin as Course in General Linguistics, New York, 1959) (cited in Crystal, 1992 p. 307), that the conception of language as a system of mutually defining entities which yields a major influence on social schools in linguistics, such as the Prague school, the Geneva school and glossematics. He defines language as "a system of signs that express ideas" (Hawkes, 2004, p.13). The linguistic sign can be dealt with in terms of the relationship between concept and sound image. Saussure (1913) bridges "concept" with the combination of "sound-image" or signified with signifier which are considered as the two sides of the sign.

The signifier is the sign vehicle; while the signified is the meaning. The signifier is the form that the sign represents whereas the signified is the concept (image) that the form takes. Saussure elaborates that words are signs which have two sides: a mark, which he calls the significant or signifier and a concept which he calls the signified. A sign is not the link between a thing and a name but between a concept and a sound pattern. When you think about a tree, the tree as an object is the signified and the written form is the signifier which represents the tree as coded culturally to our minds (Sert, 2006, p.107). Hawkes (2004) remarks the arbitrariness of the relationship between the signifier and the signified that makes language conservative in nature. It also serves to guarantee the "structural" nature of the system in which it occurs (p. 14).

Eco (1976) considers a sign as "everything that can be taken as standing for something else." (P.16). According to pierce (1977) "a sign is something which stands to somebody for something in some respect" (p.72). He adds that signs are divided into three types: icons, indices and symbols. Icons are the signs which are related or similar to the objects they stand for by virtue of some physical resemblance. Indices are the signs that relate physically to the objects they stand for because they are part of the event or the object for which they represent. For example, smoke underlines the existence of fire because the two are part of the same phenomenon. Symbols are the signs arbitrarily linked with their 
objects. For example, the word "dog" stands for an animal. Hawkes (2004) states that a diagram or a painting has an iconic relationship to its subject by virtue of its resemblance of it (p.105). It is the signifier to its object signified in iconic mode. An index has association with its reference. It is considered as a sign which refers to the object. It is affected by its object and has some qualities in common with that object. In the index, the relationship is concrete, actual and usually of a sequential, causal nature. The pointing finger is a signifier whose relationship to its signified is indexical in mode. A knock on the door is an index of someone's presence and the sound of car's horn is a sign of the car's presence in the same mode.

The word symbol is used to designate the linguistic sign or what is called signifier. Unlike icon and index, Pierce considers the symbol as conventional. Icons and indexes are not conventional (Standford Encyclopedia of Philosophy, 2010, p.5). In the symbol, the relationship between the signifier and the signified is arbitrary.

It requires the active presence of the interpretent to make the signifying connection. A symbol has an arbitrary relationship with its referent. A word or an image is symbolic when it implies something more than its meaning. It has a wider unconscious aspect. Sert (2006) points out:

A symbol is a mode in which the signifier does not resemble the signified but which is fundamentally arbitrary or purely conventional so that the relationship must be learned (numbers, national flags, particular languages, Morse code, etc).Icon is a mode in which the signifier is perceived as resembling or imitating the signified (cartoon, portrait, imitative gesture, etc) (p. 110).

Chandler (2002) (cited in Sert 2006 p.110) argues that "an index is mode in which the signifier is not arbitrarily, but directly connected to the signified as in the relationship between fire and smoke."

The triadic relationship of object $(\mathrm{O})$, sign vehicle (S) and interpreting (I) can be represented as follows:

Icon: $\mathrm{O} \longrightarrow \mathrm{S} \longrightarrow \mathrm{I}$

Resemblance A significant outcome is produced in the interpreter's mind by forming a relationship that resembles the object.

Index: $O \longrightarrow S \longrightarrow I$

Real connection A significant outcome is produced in the Interpreter's mind by "noticing" the object.

Symbol: $O \longrightarrow S \longrightarrow I$

Rule A significant outcome is produced in the interpreter's mind by forming a structure that refers to the object

Mc Neil (1974,p.42) (cited in Ibrahim, 2005 p.11).

Gestures are the use of motions of the human body as a means of non-verbal communication. Davaninzhad (2009) states:

One of the most frequently observed, but least understood clue is a hand movement. Most people use hand movement regularly when talking. It can indicate a particular meaning, feeling or intention; while some gestures (e.g., a clenched fist) have universal meanings, others do not. (p.4)

O.K gesture has different meanings in different cultures and societies. Putting your index finger in your thumb means in America everything is good; while in France it means a sign of insult (ibid). Facial expressions reveal the attitude of the speaker. For example, a smile can communicate the acceptance of an individual's answer while raised eyebrow means disagreement.

However, many body gestures and verbal non-linguistic actions other than verbal linguistic utterances are culture oriented to the extent that they may mean something in one location of a peculiar dialect but nothing or at best something different in another. Somebody movements or non-verbal gestures like side-movement of the head, lifting movement of the head or shoulders or nodding are more culture bound than verbal gestures. A side movement of the head could mean rejection in Jordan or "no way" while this same non-verbal action could mean acceptance somewhere else in the Arab world. So is the case with face lifting which could mean disagreement in one specific culture and agreement in another.

This applies to many verbal non-linguistic actions other than verbal linguistic utterances, like /tji'/, / $: /$ and /ju: / in the Arab world and like /pu: / in England could signal different attitudes in different places and different dialects. /tji'/, in Iraqi Arabic dialect is a sound underlying rejection and disagreement which is purely peculiar of an Iraqi communicative convention. Nevertheless, "a long $/ \int /$ is a sound underlying a request or a demand for silence and this sound is normally coupled with the placement of the forefinger on the lips. This sound-gesture action can be viewed as rather universal. In Jordan, /ju:h/ is a message of boredom. It could indicate some other suggestion elsewhere. In fact, this issue is worth further investigation. Such gestures or verbal non-linguistic actions can be dealt with in the context of the sign system of icons, indices and symbols. These are culture oriented conventions which may have different or even conflicting interpretations by different interpretants in different locations and cultures.

Clearly, the understanding of a message be it verbal or non-verbal involves intralinguistic and extralinguistic factors (Robins, 1989 p.28). Some meanings are learned and understood away from any specific extralinguistic context, e.g. all red signs are warnings. To know where a request "please close the window", a polite request "would you mind closing the window" or brusque order "close the window!" would be appropriate requires a considerable knowledge of personal social relations, social convention, etc. In short, Saussure's indivisible link between the signifier and the signified is often defined by some extralinguistic presuppositions especially on sentence, not only on word level. 
To conclude, social semiotics is a branch of semiotics. It includes the use of signs to construct the life of community. Societies differ in their conception of signs. A sign used by one society may imply a different message in another. For example, the color red indicates danger and prohibition in Jordan, whereas in India represents life for people. Lemke (1990) states that social semiotics is a theory of how people make meaning in social context.(p. 186 )

\section{PEDAGOGICAL IMPLICATIONS}

In spite of Chomsky's statement at a language teaching conference at Northeast University in the United States that linguistics has no direct relation with the teaching of languages, the fact remains that the two disciplines are closely related and interrelated. Chomsky (1966) remarks "I am, frankly, rather skeptical about the significance, for the teaching of language, of such insights and understanding as have been attained in linguistics and psychology".

Semiotics as the study of signs has been an area of interest to linguists and educationalists. The application of the semiotic approach to education has recently gained significant interests and it emerges as a new field of study called educational semiotics. Stables and Gough (2006) state:

It is important to note that the semiotic perspective argued for here is not merely an application to educational theory of the work regularly done by semioticians. It is rather a theory of learning and choice grounded in a view of living as semiosis. (p. 274).

Erton (2006) assures the importance of educational semiotics:

Semiotics is a very influential and essential field of study, because by making use of signs the learners are able to achieve a lot of information on various fields such as, literature, art, architecture, psychology, anthropology, philosophy, etc. (p.75)

This is ascribable to the importance of teaching foreign languages and target culture. The importance of using semiotic signs in education is due to the fact that culture and society play an essential role in defining the learning environment. The culture is intermingled with social signs and social codes. Signs have different meanings in different cultural contexts. Lemke (1990) remarks that "social semiotics is a theory of how people make meaning in social contexts." (186). Accordingly, foreign language learning is considered as a product of the foreign culture. In ELT classes, the teacher may resort to imitative gestures, pictures and visualized materials associated with the target culture which is part of a foreign language.

This will help students draw an analogy between their native culture and the target culture and this would facilitate learning the foreign language as it helps highlight areas of difficulty in language learning.

One of the objectives of educational semiotics is that the teacher should have knowledge of these signs and develop the materials and techniques for the teaching atmosphere. The teacher ought to visualize the learning materials according to the principles of educational semiotics and to the relations between signs. The results may become promising and lead to effective learning. Using signs in the classroom gives learners a lot of information about different fields. The use of semiotic elements (visual material) like flashcards and wall pictures helps the learners contextualize the meaning of the vocabulary within their minds and facilitates the learning process by passing information to the longterm memory. Facial expressions reveal the attitude of the teacher which can also be used effectively in teaching. For example, a smile can communicate the acceptance of the learner's answer or it can be used as a stimulus or a reward to the learners. Raised eyebrow means disagreement and gives hints for the learner to change or modify his answer, as noted above.

The curriculum is also influenced by the semiotic approach. Books, flashcards and wall pictures ought to contain a set of symbols which can be useful in the affective domain of learning. Erton (2006) states:

The cassette signs indicate the time of a listening activity, a smiling face indicates the success of the activity, the tick and the cross sign refer to a true/false activity and different colors in a textbook might represent different sections of language study: speaking, reading, listening, etc. (p. 85)

The teacher may also use such semiotic symbols as a part of his techniques in teaching foreign languages because the use of signs and symbols by teachers and learners is an effective and influential technique in teaching foreign languages. Erton asserts:

"Since semiotics is the combination of signs and symbols to communicate information, the student, and the teacher can make use of a number of signs, some of which are iconic and some are symbols. Thus, it can be said semiotics is a fundamental issue to be considered in language teaching pedagogy." (ibid P. 74).

Semiotics can be used to facilitate teaching new vocabulary. The teacher can accompany the educational sign like a no-smoking sign by a sentence or a phrase so that the learners will recall them easily. Sert (2006) states "while teaching new vocabulary, if new words are reinforced with relevant pictures, the result will be the long-term coding of this target language item.'(p.109) Today's textbook and teaching material teem with colorful pictures aimed at creating a makeshift learning atmosphere and often creating a real-life learning setting.

Willis (1981) (cited in Sert, 2006 p.109) conducted a study on two groups: the experimental group and the traditional group. The teacher in the experimental group used the following symbols in evaluating the students' written products:

$\mathrm{s}$ - spelling

$\mathrm{s} / \mathrm{p}$ - singular, plural

$\mathrm{c}-$ concord (subject - verb agreement) 
w.o - word order

$\mathrm{p}$ - Punctuation

$\mathrm{t}$ - tense ,etc

The teacher in the traditional group used long sentences to evaluate the products of his students. The researcher found that the experimental group performed better than the traditional one.

\section{SAMPle Classroom Application: Speaking}

a. The Reading Text: Glassmakers of Na'ur (Cobb et al, 1997,pp.100-101).

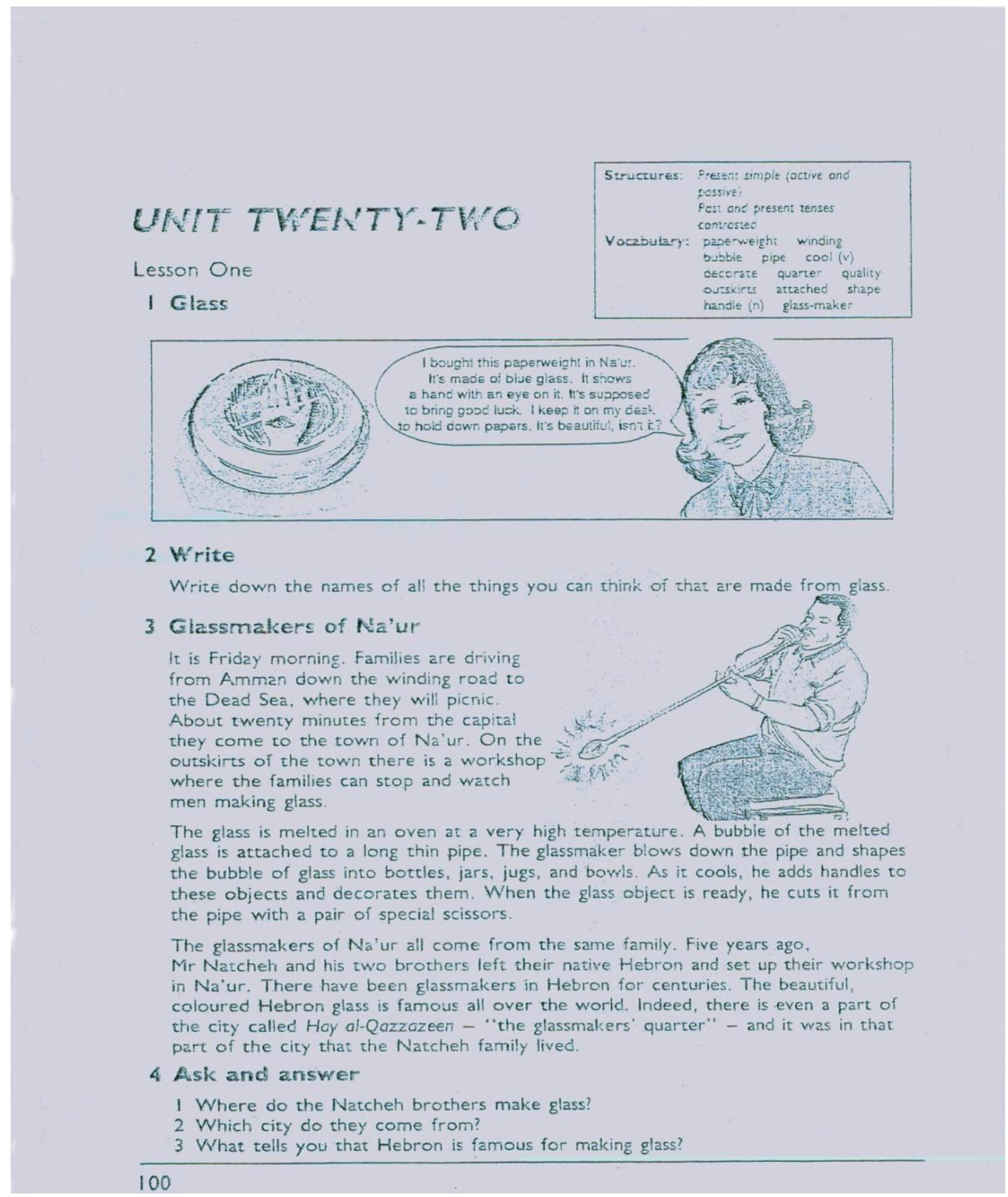

b. Semiotic signs and symbols: The semiotic signs and symbols of this activity (speaking) are: map of Jordan and the West Bank, Wall picture of old glass factory symbolizing the Jordanian culture and pictures of how the glass is made in a traditional glass factory.

c. Procedure: By making use of the above semiotic symbols, the students are asked to locate the site of Na'ur and Hebron on the map. Under the guidance of the teacher, the students are asked to talk about these cities and how we can travel to these cities from Amman. The map of Jordan and the west Bank will be helpful. The teacher offers the following pictures, which show the stages of how to make glass in the traditional glass factory: 


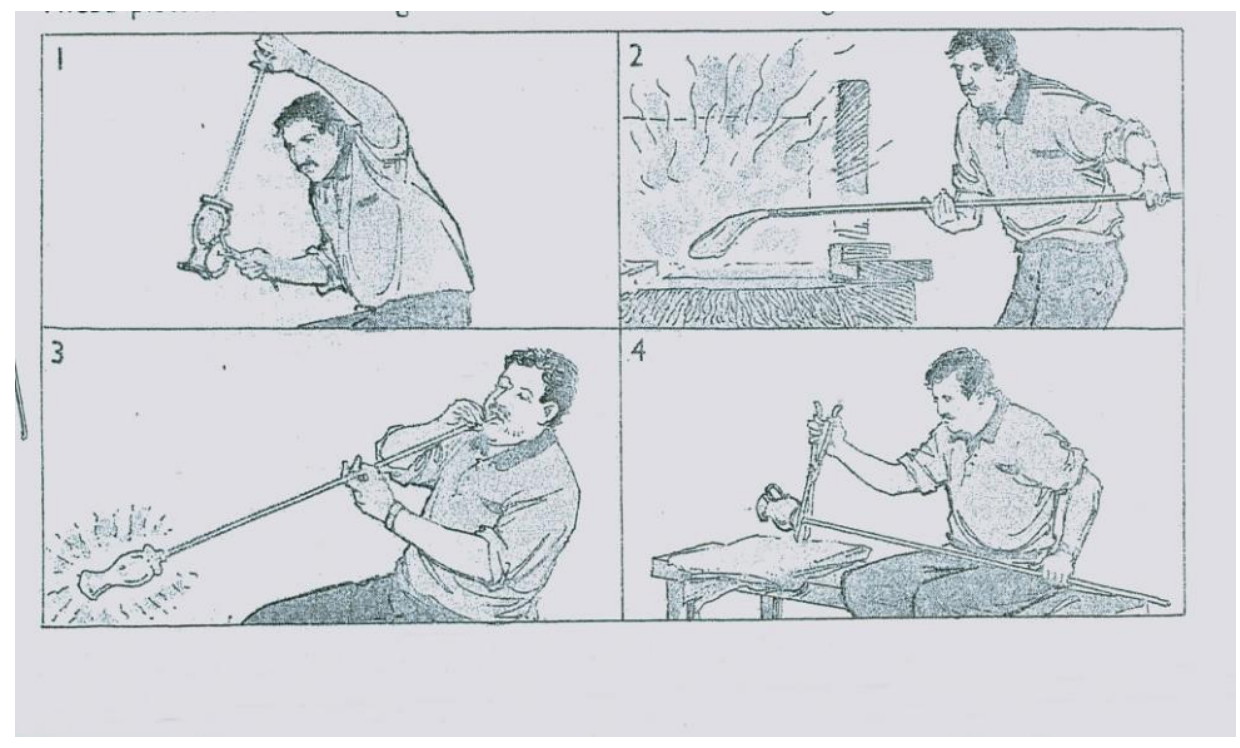

These pictures are presented as semiotic signs. The teacher asks the students to put the pictures in the right order and to make up their own questions. One group can ask another (or one partner to another in a pair). For example, they could ask the following questions:

-Is the oven hot or cold? Why?

- What is the pipe for?

-What is on the end of the pipe?

- What is the man going to do with the pipe?

Students are more likely to remember language when it is presented visually through semiotic signs. Pictures of an old traditional glass factory and a new one which appears as semiotic signs are presented. The students are asked to compare between them. As a response to the students, the teacher's silence may help foster the student's self-reliance and his initiative. Teacher's gestures will help facilitate learning and they are easily understood because such gestures are culturally familiar to both the teacher and his students. They would give quick responses while carrying out the activities.

\section{CONCLUSION}

Language as a means of communication has been under focus in the last century by researchers and linguists like Saussure (1913), Jacobson (1974), Chomsky (1957), Krisitva (1986), and others. Their main concern, among other things has been the relationship between the sign and the object and the transfer of the cultural elements to language environment. Communication is the exchange of ideas among people. All forms of communication can be classified as verbal and non-verbal. Verbal communication is a conversation between two or more individuals by using the speech organs to convey a message. Non-verbal communication is the process of communication among people through wordless messages, such as gestures, body language, facial expressions and signs. Some scholars like Saussure, pierce, and others have tackled the sign in the domain of communication.

Throughout the paper, the contribution of semiotics to education has been tackled. In order to maximize the efficiency of foreign language teaching, the teacher should acquaint his students with the semiotic signs to facilitate learning. The importance of using semiotics in education can be attributed to the fact that culture and society play an effective role in the learning environment as many scholars and researchers in this field have stressed.

\section{REFERENCES}

[1] Al-Mutawa, Najat and Taiseer Kailanin. (1994). Methods of Teaching English to Arab students, London: Longman.

[2] Chomsky, N. (1979). On Cognitive Structure and Development: A Reply to piaget. In (Ed.) Massioni palmarini, Language and Learning (pp.35-52).

[3] Chomsky, N. (1966). Linguistic Theory, Northeast Conference on Research and Language Learning, Northest University.

[4] Chomsky, N. (1957). Syntactic Structure. The Hague: Mouton and Co.

[5] Crystal, D. (1992.) A Dictionary of Linguistics and Phonetics, London: Blackwell.

[6] Cobb et al. (1997). PETRA: Students' Book 5, Ministry of Education, Jordan.

[7] Davanizhad, k. (2009). Cross-Cultural communication and Translation in Translation Journal, vol.13, No.4.(pp.1-10)

[8] Dinneen, Francis p. (1979). An Introduction to General Linguistics, New York: Holt, Rinehart and Winston Inc.

[9] Eco, Umberto. (1976). A Theory of Semiotics, Bloomington: Indiana Up, London: Macmillan.

[10] Erton, I. (2006). Semiotic Nature of Language Teaching Methods in Foreign language Learning and Teaching in Journal of language and Linguistic Studies, vol.2, No.1: (pp.73-86)

[11] Fromkin, Victoria et al. (2003). An Introduction to Language, Boston: Heinle. 
[12] Hawkes, T. (2004). Structuralism and Semiotics, London: Routledge.

[13] Ibrahim, Jalal (2005). Linguistic Sign with Reference to Translation in Al-A'daab, No. 72 (pp.1-29).

[14] Johnson, K and H. Johnson. (1999). Encyclopedic Dictionary of Applied Linguistics, Oxford: Blackweel publishers Ltd.

[15] Jacobson, R. (1974). Main Trends in the Science of Language, New York: Harper.

[16] Kristiva, J. (1986). The Kristiva Reader, Oxford; Basil Blackwell Ltd.

[17] Lemke, J. (1990). Talking Science: language, Learning and Values, Ablex Norwood N.J.

[18] Lyons, John. (2004). Language and Linguistics. An Introduction, London: Cambridge University press.

[19] Peirce, C.S. (1977). Semiotics and Signifies. Ed Charles Hardwick. Bloomington I.N.: Indiana University Press.

[20] Robins R.H. (1989). General Linguistics, Fourth Edition, London: Longman.

[21] Saussure, Ferdiand de. (1913). Course in General Linguistics, London: Fontana.

[22] Sert, Olcay. (2006). Semiotic Approach and its Contribution to English language learning and Teaching, Hacettepe Univerisitesi Egitim Fakultesi Dergisi, 31,(pp106-114).

[23] Standford Encyclopedia of philosophy. First Published Fr: Oct.2006, Substantive Revision Mon. Nov. 15, 2010.

[24] Stables, Andrew and Stephen Gough. (2006). Toward a Semiotic Theory of Choice and of Learning, Educational Theory, vol 56, No. 3,(pp.271-286).

[25] Yule, George. (2001). The Study of Language, Cambridge: CUP.

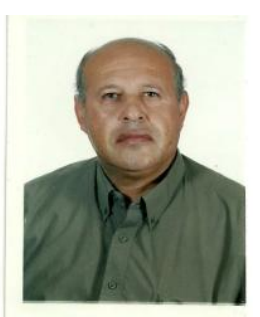

Ibrahim Mohammad Abushihab was born in Jordan 1958. He got his BA in English and MA in TEFL from Yarmouk University/Jordan (1980,1986), whereas PhD degree in Applied Linguistics was received from Gazi University/Turkey (2003). Over the past 28 years he has been teaching English as a foreign language to Arab students in the Ministry of Education in Jordan, Aljouf University (Saudi Arabia) and Alzaytoonah Private University of Jordan. Since then, he has been doing research in the field of linguistics, discourse analysis, applied linguistics and contrastive analysis. Dr. Ibrahim Abushihab is currently head of English Department at Alzaytoonah University of Jordan. 